\section{A integração do léxico português no ensino da língua cokwe}

\author{
Portuguese lexical integration \\ on the teaching of Cokwe \\ language
}

Ana Alexandra SILVA (Universidade de Évora) aasilva@uevora.pt

Albano Agostinho EDUARDO (CEDES) mulombi2015@gmail.com

Recebido em: 31 de jul. de 2020. Aceito em: 23 de ago. de 2020.
SILVA, Ana Alexandra; EDUARDO, Albano Agostinho. A integração do léxico português no ensino da língua cokwe. Entrepalavras, Fortaleza, V. 11, n. esp., p. 103-119, ago. 2021. DOI: 10.22168/2237-6321-10esp2014.

Resumo: A língua portuguesa, enquanto entidade cultural abstrata, é exteriorizada como um instrumento de comunicação, presente em África, com maior expressividade em Angola e Moçambique (HAGEMEIJER, 2016), desde o século XV, num período de contacto continental. O presente artigo pretende contribuir para a discussão em torno do papel da língua portuguesa em Angola, ou melhor, para a multiplicidade de papéis que a língua oficial acaba por assumir no quotidiano dos seus falantes. Iremos centrar a nossa análise numa das línguas nacionais, o cokwe, tentando mostrar em que medida esta língua nacional interage com a língua oficial. Destacamos a integração desta língua nacional no subsistema de ensino primário, através de um programa de ensino bilingue. Haverá, pois, lugar a interferências que ocorrem no sentido cokwe-português e, mais tarde, português-cokwe. Para tal, iremos destacar as estratégias de integração lexical (mudança, nasalização e assimilação) e processos de acomodação dos estrangeirismos. Recolhemos exemplos que visam demonstrar como as unidades afixais são determinadas pela atração da natureza estrutural e semântica da raiz.

Palavras-chave: Léxico. Integração. Cokwe. 
v. 11 (esp.)

103-119 ago. 2021

Abstract: The Portuguese language, in its abstract and cultural form, is externalized as a communication tool in various countries, including Africa, with greater prevalence in Angola and Mozambique (HAGEMEIJER, 2016) since the 15th century, during a period of colonial contact. This article aims to contribute to the discussion on the role of Portuguese language in Angola, more specifically the multiplicity of roles that the language plays in the daily lives of its speakers. We will focus our analysis on one of the national languages, the Cokwe language, and the extent to which this national language interacts with the official Portuguese language. We will emphasize on the integration of Cokwe in primary education subsystem through the means of a bilingual education program. Interference is bound to occur between the two languages, with Cokwe influence on Portuguese, and vice-versa. To this end, we will highlight lexical integration strategies (change, nasalization and assimilation) and accommodation processes of foreign words. We will collect examples to demonstrate how prefixes and suffixes are chosen according to the structural and semantic nature of the root word.

Keywords: Lexicon. Integration. Cokwe.

\section{Introdução}

O presente trabalho visa contribuir para um traçar do retrato da língua portuguesa em Angola. A multiplicidade de papéis que ocupa no quotidiano (língua oficial, língua segunda, língua materna e língua estrangeira) faz com que esteja mais suscetível às interferências das línguas bantu. Iremos centrar a nossa análise numa das línguas nacionais, o cokwe, tentando mostrar em que medida esta língua nacional interfere com a língua oficial. Será nosso objetivo demonstrar as estratégias de integração lexical adotadas.

A metodologia compreende o desenvolvimento das seguintes etapas: num primeiro momento, procederemos à contextualização sociolinguística, para num segundo momento se afunilar para o caso específico da língua nacional, o cokwe. Fundamental, igualmente, será o enquadramento no subsistema de ensino primário da língua oficial e da língua nacional, de forma a melhor explicar as estratégias de integração lexical. A amostra do corpus utilizada é representativa, demonstrando as estratégias de integração dos empréstimos, bem como o processo de acomodação sofrido pelas unidades lexicais. Procederemos ao exame das formas, de modo a mostrar a existência de distinções nas duas línguas.

Angola é um país multilingue e, pode mesmo considerar-se, que vive uma situação de diglossia', o que está na base de uma maior difusão da língua portuguesa, em consequência da sua valorização como língua oficial. Acresce, ainda, a mobilidade populacional dos anteriores locais de maior implantação colonial (litoral), para o interior e leste do país.

${ }^{1}$ Dada a relevância do português sobre as línguas locais (Cf. EDUARDO, 2016). 
Da exploração colonial (século XV)ª̀ paz (2002), são várias as fases do percurso da língua portuguesa. Desde os exploradores europeus à herança histórica, houve sempre contacto com a realidade sociocultural nacional. Porém, é no interior do país que esta interação encontra continuidade expansional ${ }^{3}$ em outras comunidades bantu e não bantu (lunda, tucokwe, ngangela, mbunda, ibangala, ambundu, ovambu, entre outras), cujos sistemas linguísticos apresentam convergências e divergências tendo em conta a origem e o posicionamento geográfico.

Ressalta-se aqui a comunidade tucokwe como uma das mais conhecidas 4 etnias de Angola, representando um dos ramos do então império lunda (MANASSA, 2014; LIMA [s.d.]) - como um todo etnolinguístico resultante da região central de África (República Democrática do Congo/RDC, Zâmbia, Zimbabwe, Tanzânia e Angola). Pelo prestígio da sua história e cultura (caça, utilização do ferro, escultura e dança), os tucokwe encontram uma irrefutável referencialidade numa arte singular que, para além de um contágio a povos circunvizinhos, é uma representatividade transcontinental de um todo nacional.

Presentemente, se por um lado se realça a coabitação multicultural em Angola, por outro, é o seu enriquecimento (séc. XIX), com o reforço de um povoamento distinto, portugueses e brasileiros ${ }^{5}$, que veio a ser determinante para a atual configuração sociolinguística (INVERNO, 2018), em particular nas áreas de influência dos lundacokwe. Importa aqui recordar que o termo cokwe é o que, entre as línguas bantu, aparece com muita diversidade gráfica tendo em conta as várias tentativas de reproduzir a oralidade em escrita: kokwe, kioco, chokwe, tioco, quioco, Utchokwe, Tutshiokwe, Kioke, Khioko, Kiokjo, entre outros (BEVILACQUA, 2016). Adota-se "cokwe", grafia adaptada, em conformidade com a atual proposta de uniformização ao nível do ensino bilingue.

\footnotetext{
${ }^{2}$ Segundo Inverno (2018), a presença da língua portuguesa, numa primeira fase, limitou-se ao litoral e ao interior, até 30okm ao longo dos rios Kwanza e, posteriormente, Kunene (séc. XVIXVIII), sem impacto linguístico nas comunidades locais.

${ }^{3}$ Hoje a língua portuguesa é falada num espaço de cerca 24.383.301 habitantes (INE, 2014).

${ }_{4}^{4}$ A quarta língua nacional mais falada em Angola (português, umbundu, kikongu, kimbundu e cokwe), segundo dados do INE 2014 (INE, 2016).

5 Segundo Inverno (2018), foi uma presença motivada pela conferência de Berlim (1884-1885). Hoje, justifica-se pela cooperação em vários domínios com destaque para a área da construção.
} 
v. 11 (esp.)

103-119 ago. 2021

Foi também naquele século, com a presença da Diamang6, administração local, que o contacto com a comunidade lunda-cokwe conheceu outro impulso por meio de uma mistura de objetos europeus com os locais (BEVILACQUA, 2016), como uma forma de exploração e conservação do património africano (JORGE, 2008). A língua portuguesa e a língua cokwe são os instrumentos de maior alcance ao nível da administração e comunicação social, não obstante a presença de outros grupos minoritários-linguísticos (congolenses, chineses, malianos, entre outros). É neste quadro que o português se constitui no maior vetor de relações, em concorrência com o cokwe, chegando a desempenhar papéis de autêntica língua franca, ainda que a níveis e contextos diferentes.

Atualmente, a língua portuguesa, ao estar implantada em quase todo o território, é utilizada como língua oficial, língua segunda, língua primeira e língua estrangeira. É nestas dimensões que perde o rigor inicial e se transforma numa língua vulnerável às interferências das línguas bantu (NZAU; VENÂNCIO; SARDINHA, 2013), tentando, desta forma, satisfazer as necessidades comunicativas dos utilizadores. Assim sendo, é compreensível que na incapacidade de uma reprodução fiel do sistema linguístico europeu ocorram interferências (desvios, hibridações etc.) resultantes de uma especificidade local, angolar ${ }^{7}$, expandindo-se como um processo prévio de aculturação.

Não obstante a limitação e o estado degradado das vias de circulação, é com a implementação do sistema multipartidário (1992) que a região conheceu maior abertura, dando início à mobilidade populacional, atividade comercial, necessidade de maior escolarização da população e dos funcionários do aparelho governamental. Tornavase necessário referenciar a flora e a fauna, mas também a realidade sociocultural, agora influenciada pela industrialização e pela tecnologia. São essas evidências que levam a comunidade tucokwe a resistir menos à inevitável força da globalização, veiculada pelo português europeu e, com isto, a submissão, a aceitação e a adaptação do seu léxico que permite aos novos falantes ter contato com as culturas externas ao universo bantu.

\footnotetext{
${ }^{6}$ Antiga empresa de exploração de Diamantes de Angola.

7 Entendemos relacionar esta variedade, ainda em construção, com o topónimo Angola (Cf. EDUARDO, 2016). Não obstante existir uma língua (Santomense) com esta designação, nada impede que esta especificidade seja também assim designada.
} 


\section{A língua cokwe no atual contexto}

Sobrepondo-se à língua urundu/ulunda/lunda8 e às suas subvariedades (uxinje, usongo, ubangala, ukali, por exemplo), o cokwe constitui-se como língua franca do leste de Angola, por refletir a herança de um domínio sociocultural e histórico nesta região (CAPPELLO; IVENS, 1881; DIAS, 2003), com uma reconhecida influência nas comunidades de Malanje, Vié, Wila, Kunene e Kwandu Kubangu. Apesar de ser uma comunidade caracterizada, durante o período de expansão, pelo nomadismo, o seu predomínio foi notabilizado por um poderio guerreiro e de conquista, representação artística e pelos recursos naturais ${ }^{9}$ nos espaços dominados (SANTANA, 2016).

Se na vertente sociolinguística, por exemplo, o uso de kikongu (mukongu), para um falante da variante kizombu, implica a mediação da variante kimanyanga (RDC) ou kisikongu (Angola) para a sua compreensão (KUKANDA, 2000), em oposição, na região Leste, não sentimos o mesmo com a língua cokwe. Esta goza ainda de inteligibilidade desde a RDC até à parte Sul (interior das províncias de Kunene e da Wila-Matala), assim como a Sudeste e Nordeste das províncias de Malanje e do Vié. Apesar das variantes ${ }^{10}$ em coabitação, trata-se de uma língua nacional ${ }^{11}$. Isto comprova-se pela estabilidade que apresenta a nível linguístico e político.

Não obstante a ausência de homogeneidade das línguas, quando se analisa a inteligibilidade entre povos longínquos, verifica-se a compreensão mútua no uso da língua segundo regional. Tal deveuse ao facto de o corredor Leste, durante os conflitos armados, ter sido isolado do resto do país em termos de vias de comunicação.

Hoje, enquanto corpo dinâmico, a língua cokwe está sujeita ao crescimento e ao desenvolvimento, de modo geral, da sociedade

\footnotetext{
${ }^{8}$ Língua predominante no ex-império lunda, que incluía a etnia tucokwe, antes do século XIX, cuja expansão, por meio dos dissidentes Cilwanje, Cinguri, Nzumba Watembo e Cinhama está na origem de comunidades linguísticas nas regiões de Malanje, Lundas, Muxiku e Vié.

9 Borracha, mel, animais de porte, marfim (SANTANA, 2016) e, hoje, diamantes, madeira e inertes para construção. Tendo em conta o anterior centro de radiação, concordamos com Martins (1990) quando refere que os tucokwe estão na origem dos nomes dos rios e das regiões onde exerceram o domínio (Zambeze, Kwangu, Kwanza, Kwandu kubangu, Xa-utale, xa-ulimbo, Muxiko, kafunvu, etc).

10 Ulunda, cokwe, mataba, ukongu ou badinga e mai (Lunda-Norte); cokwe (Lunda- Sul); ulunda-wa-xinde, ulunda-ndembu, cokwe (Moxiku); cokwe (em parte das províncias de Kwandu Kubangu e Bié), segundo Kukanda (2000, p. 113).

${ }^{11}$ Com base na Resolução n³/87 (Alfabeto das seis línguas nacionais) e Lei de Bases do Sistema de Educação aprovada em 2001.
} 
v. 11 (esp.)

103-119 ago. 2021

contemporânea. O que quer dizer que, quanto mais inovações existirem na vida social, económica, política, tecnológica etc., maior será o enriquecimento desta língua e, concomitantemente, a sua instrumentalização. Do lado oposto encontrar-se-á a estagnação, correndo o risco de se vir a tornar uma língua morta dada a rápida expansão e penetração da língua oficial neste espaço e nas respetivas culturas. Poderá isto significar que o desenvolvimento da língua cokwe é, também, de maneira consciente, intrínseco à abertura e à aceitação daquelas influências globalizantes.

No entanto, dada a limitação das línguas nacionais, a língua portuguesa constitui-se como elemento preponderante na mediação entre a realidade local e a estrangeira (e vice-versa). Por meio da língua oficial são incorporados novos elementos no ambiente sociocultural das comunidades ${ }^{12}$ angolanas, cujas repercussões são notórias ao nível do ensino e das investigações científicas.

\section{As línguas portuguesa e cokwe no sistema de ensino}

De acordo com a Declaração Universal dos Direitos Linguísticos (2001), nos artigos $9^{\circ}$ e $10^{\circ}$, há um explícito reconhecimento de que "Todas as comunidades linguísticas são iguais em direitos" e, em consequência disso, "[...] têm direito a codificar, estandardizar, preservar, desenvolver e promover o seu sistema linguístico [...]". Essas prerrogativas são assumidas pelo governo angolano, por meio dos seus instrumentos jurídicos, como um compromisso perante a comunidade nacional e internacional ao manifestar, no art. $79^{\circ}$, ponto 1 , da Constituição a sua intenção em promover ao Estado "o acesso de todos à alfabetização, ao ensino [...]." (ANGOLA, 2010, p. 28), admitindo também a possibilidade de o ensino ser administrado "[...] nas línguas nacionais" (art. 19º). No entanto, e segundo a Lei de Bases do Sistema de Educação Nacional, esta opção não pode comprometer a aquisição da língua portuguesa. É no ponto 1 do artigo acima citado que o governo reafirma e confere vantagem à língua de origem europeia sobre as locais, hoje consubstanciada em língua segunda (para a maioria), língua primeira (para a minoria), língua veicular, língua estrangeira (minoria) e língua oficial (de uso institucional obrigatório).

\footnotetext{
${ }^{12}$ É hoje notável a tendência crescente de a língua portuguesa ser também a língua maioritária nos centros rurais, influenciados pelo que já acontece nos centros urbanos. Os serviços administrativos e públicos (incluindo o sistema escolar) fazem com que haja uma geração que adopte o português como língua materna. É este desenvolvimento que, de modo genérico, confirma as tendências apresentadas pelo INE.
} 
Enquanto parte dos fatores concorrentes à proficiência, a marginalização das línguas locais, desde o século XVI, é reconhecida como estando na base dos efeitos negativos na aquisição da língua oficial (CARRASCO, 1988), o que leva o governo a uma revisão e atualização de políticas linguísticas e a proceder a um correlato processo de valorização (ZAU, 2002; QUINO, 2005; CHICUMBA, 2013), reafirmando a identidade das suas principais comunidades étnicas.

Analisar a coabitação entre a língua portuguesa e a língua cokwe é, simultaneamente, refletir sobre a norma europeia, hoje quase figurativa ou pouco efetivada, e sobre o angolar (fusão da variedade europeia e as línguas locais), por meio das quais se processa a aceitação e a partilha de elementos culturais, mesmo que esta não ocorra de forma proporcional. A experimentação do ensino bilingue, que incide no subsistema de ensino primário, é a evidência de um esforço, por parte das autoridades, em diminuir o fosso entre a língua nacional e a língua portuguesa.

É no âmbito do atual projeto de ensino bilingue que a língua cokwe, a par do umbundu, kimbundu, kikongu, ngangela, oshykwanyama e fyiote ${ }^{13}$, é inserida na grelha curricular ${ }^{14}$, com o propósito de permitir um ensino mais inclusivo e democrático. No fundo, é, entre outras vertentes, nesta linha programática que se enquadra esta instrumentalização que visa atender, para além da homogeneidade no seu uso formal, a mediação ao longo da aquisição da língua oficial de ensino, enquanto língua segunda, num ambiente de interferências culturais e linguísticas. Esta caraterística é comum a outros países que adotaram o português como língua oficial. Vejase, por exemplo, o caso de Timor-Leste. O contexto é, tal como em Angola, multilingue, havendo lugar para duas línguas oficiais e várias línguas nacionais (CARIOCA, 2016, p. 430). Rumo semelhante é seguido em Moçambique. Segundo Cossa (2007, p. 44), "há mais falantes do português na faixa etária dos 15-24 (aproximadamente $45 \%$ ), seguido pela faixa de 7-14 (aproximadamente 30\%) e pela dos 25-39 (aproximadamente 30\%)". Como se poderá deduzir, a restante faixa etária é a detentora da identidade cultural e linguística nacional.

${ }^{13}$ Lê-se no Projecto Estratégico de Integração das Línguas Nacionais (INIDE, 2015).

${ }^{14}$ De acordo com o Plano de Estudo do Ensino Primário, atualizado, integra as seguintes disciplinas: Língua Nacional, Língua Portuguesa, Matemática, Estudo do Meio, Ciências da Natureza, História, Geografia, Educação Moral e Cívica, Educação Manual Plástica, Educação Musical e Educação Física. (EDUARDO, 2019, p. 47). 
v. 11 (esp.)

103-119 ago. 2021

Enfatiza-se, neste processo, a incorporação de unidades lexicais do português no sistema linguístico cokwe, cuja aceitação é indispensável na aquisição de uma metalinguagem em fases diferentes: cokwe-português e, posteriormente, português-cokwe na consolidação dos saberes ao longo das $1^{\mathrm{a}}-4^{\mathrm{a}}$ e $5^{\mathrm{a}}-6^{\mathrm{a}}$ classes. Destaca-se as componentes morfológicas e lexicais por serem áreas bastante presentes nos atuais materiais didáticos, permitindo desta forma a integração da língua cokwe neste ensino globalizado. Esta integração acontece por meio de empréstimos que satisfazem as exigências dos utilizadores, dando origem a inovações linguísticas.

\section{Estratégias de integração lexical}

A nossa questão de pesquisa prende-se com a capacidade que o sistema linguístico cokwe terá (ou não) para aceitar o dinamismo inerente ao mundo global que hoje existe. Tal como as línguas indoeuropeias, enquanto corpos dinâmicos, as línguas nacionais estão sujeitas a influências da globalização, expressa, cada vez mais, nas interações culturais que determinam as inovações. A coexistência das línguas nacionais, tanto nos espaços tradicionais, quanto nos de expansão, passa pela aceitação de influências e alterações de determinados paradigmas nos seus sistemas linguísticos.

O tempo pode ajudar a responder a essa inquietação dado o estado atual de políticas linguísticas em Angola. No entanto, há que destacar que, enquanto a língua portuguesa evoluiu, diferenciando-se no tempo e no espaço, as línguas nacionais não o fizeram da mesma forma. O confinamento dos espaços em que a língua cokwe existe, quer em termos físicos, quer em termos culturais, fez com que a evolução não existisse de forma a satisfazer as necessidades comunicativas dos povos que a utilizam. A abertura e inovação do seu sistema linguístico são elementos essenciais, sendo a área lexical a mais permeável a outras referencialidades. A pressão sociocultural obriga à integração gradual, por via da morfologia lexical, de novas experiências, novos desejos e novas influências, não obstante, segundo Nogueira (1952), do ponto de vista de reprodução gráfica, nunca serem equivalentes aos originais.

A composição do léxico é uma caraterística que opõe as principais línguas nacionais entre si. A morfologia nominal vaise diferenciando cada vez mais à medida que se afasta da raiz bantu (cokwe, pertencente à Zona $\mathrm{K}$ e kikongu, pertencente à Zona $\mathrm{H}$ ) e, 
parcialmente, do núcleo da variedade (ulunda, cokwe, usongo, swela, ubangala, uxinje, ulunda-ndembo, todos situados na zona $\mathrm{K}$ ).

A língua cokwe ao ser, do ponto de vista morfossintático, aglutinadora, indica quais as estratégias incorporativas das novas unidades lexicais, percebendo-se o mecanismo de aquisição ou rejeição de estrangeirismos.

A oralidade, ao preceder a modalidade escrita, continua a ser a manifestação linguística primordial na representação do social ou do mundo extralinguístico, o que justifica a intrínseca relação entre os sons e as formas lexicais, não obstante estas constituírem, às vezes, como referenciado acima, uma representação desviante da originalidade fonética. De modo geral, as unidades lexicais espelham um reajuste estrutural (VILELA, 1999), até à adaptação, para corresponderem à norma, traduzido em aglutinação, nas línguas bantu, em que os morfemas desempenham importantes funções morfossintáticas. Este procedimento permite a integração de mais unidades de referencialidades socioculturais, sobretudo do dia-a-dia, como uma extensão da correlação entre os fatores externos e os internos.

Para a integração lexical, com recurso ao processo morfológico, a língua cokwe serve-se da estratégia tradicional, consubstanciada em afixos. A incorporação dos estrangeirismos é processada por meio de prefixos, em conformidade com as classes nominais, o que permite a fixação de características compatíveis aos hábitos da oralidade e, consequentemente, a peculiar categorização das unidades lexicais. Nesta perspetiva, o facto de a língua cokwe apresentar um emparelhamento de classes nominais (SANTOS, 1962; MARTINS, 1990), à partida, atende ao requisito para a integração na principal categoria gramatical - nomes/ substantivos, o que, desde logo, levanta a outra inquietação: é o sistema de classes nominais compatível com esta necessidade integradora?

Será na reestruturação e integração de novas unidades, que se processa, com rapidez, o alargamento do léxico no sistema linguístico cokwe, uma vez que o léxico originário de outras línguas nacionais, em muitos casos, tem o equivalente em cokwe e na língua ulunda, o que torna o empréstimo, às vezes, dispensável. Todavia, atendendo à estratégia aglutinadora nesta língua, a integração obedece à seguinte categorização: 
v. 11 (esp.)

103-119 ago. 2021

Quadro 1 - Natureza dos nomes

\begin{tabular}{|c|c|c|c|}
\hline \multicolumn{4}{|c|}{ Cokwe } \\
\hline $\mathrm{N}^{\mathbf{O}}$ & Singular & Plural & Natureza \\
\hline 1 & (amigo) & ma-sepha & Humano \\
\hline 2 & (panela) & ma-ndoho (panelas) & Objeto \\
\hline 3 & $\varnothing$-mungwa $\quad$ (sal) & $\emptyset$-mungwa & Massivo \\
\hline 4 & cinyengo (tristeza) & Y-inyengo (tristezas) & Abstracto \\
\hline
\end{tabular}

Fonte: Autoria própria.

Decorre deste quadro sinóptico o seguinte: por exemplo, em (1) e (3), diante de uma estrutura frásica SVO o uso dos nomes pode apresentar comportamentos diferentes. Em sepha w-amika-na-soneke (o meu amigo está a escrever), o nome é passível de flexão em número, ma-sepha j-amika-na-soneke (os meus amigos estão a escrever). Já em kwasala $\varnothing$-mungwa (faltou o sal), a forma (flexão) é comum tanto para o singular, quanto para o plural, havendo uma silepse ao nível da concordância. Neste último, a harmonia entre o nome e a entidade não é marcada formalmente, uma vez que os nomes massivos representam generalidades, ainda que ocorra a presença dos prefixos nominais e os de concordância.

No entanto, de acordo com a categorização apresentada por Santos (1962) e Martins (1990) ${ }^{15}$, destaque para o segundo por ser mais recente, o nome sepha, com a ausência do prefixo $\varnothing$, pode flexionar para o plural masepha, condizente com a $4 .{ }^{\mathrm{a}}$ classe, por corresponder, entre outros nomes, à que satisfaz o enquadramento do plural ma, enquanto se conserva o prefixo do nome básico, como veremos adiante. A mesma estratégia não é aplicável ao nome massivo $\emptyset$-mungwa, pois ao representar entidade genérica carece de morfemas flexionais no respetivo emparelhamento, sendo por isso um "monoclasse" (MBANGALE, 1994). O prefixo $\emptyset$ é replicável por ser comum para a realização do singular e do plural em unidades morfossintáticas de género. Já em (4) nomes como cinyengo, o prefixo singular corresponde à $3^{\mathrm{a}}$ classe e flexiona em Y-inyengo, cujo prefixo é um morfema (geminado em i-inyengo) pertencente ao mesmo emparelhamento da classe (MARTINS, 1990, p. 37). Regra geral, as unidades afixais (prefixos) são determinadas pela atração da natureza estrutural e semântica da raiz, sendo esta, em última instância, a regente desta concordância ou harmonia (prefixo-raiz), e, por sua vez, do nome em relação ao todo frásico, por encadeamento de prefixos concordantes.

\footnotetext{
${ }^{15}$ Martins (1990) identifica 10 classes de substantivos, sendo que o prefixo de classe a adotar para o singular e para o plural é diferente. Para uma consulta detalhada das classes, cf. Martins (1999, p. 38-47).
} 
A integração de novos empréstimos passará pelo mesmo paradigma comportamental - submissão de novas unidades lexicais a um processo, essencialmente, de prefixação, e, em alguns casos, de infixação, mantendo-se intacta onde a aplicação se torna complexa, estranha ou mesmo irritante aos ouvidos e olhos dos mais conservadores. Será este, basicamente, o processo de aceitação:

Quadro 2 - Estratégias de integração dos empréstimos:

português $\Rightarrow$ cokwe

\begin{tabular}{|c|c|c|}
\hline Português & Estratégia de Integração & Cokwe \\
\hline Escola & Mudança & $\emptyset$-xikwola \\
\hline Gato & Nasalização & $\emptyset$-ngatu \\
\hline Açúcar & Redução & $\emptyset$-suka \\
\hline Sapato & Assimilação & $\emptyset$-saphatu \\
\hline Padre & Assimilação & $\emptyset$-phadre \\
\hline Polícia & Assimilação & $\emptyset$-phulixa \\
\hline Negócio & Mudança & $\emptyset$-mingoso \\
\hline Casaco & Assimilação & $\emptyset$-kazaku \\
\hline Hospital & Mudança & $\emptyset$-xiphitali \\
\hline Batata & Nasalização & $\emptyset$-mbatata \\
\hline Pato & Assimilação & $\emptyset$-phatu \\
\hline Livro & Assimilação & $\emptyset$-livulu \\
\hline Cenoura & Assimilação & $\emptyset$-senowola \\
\hline
\end{tabular}

Fonte: Autoria própria.

Esta integração resume-se a objetos inexistentes (kazaku, livulu) e novos desejos ${ }^{16}$ (mbatata por kathatha). Nas línguas bantu e, no caso, em cokwe, por extensão, a integração ocorre quer no contexto informal, quer no formal. Segundo Giles et al. (1977 apud CARVALHO, 2014, p. 53), no processo de acomodação destacam-se as "estratégias de convergência e divergência" em situações comunicativas que, em cokwe, correspondem a uma maneira de adaptação às regras. Neste sentido, quando o nome é resultante de outro nome, de acordo com Andrade (2007, p. 111), ocorrem, tendencialmente, modificações assinaláveis nos morfemas finais, como complemento da estratégia de adaptação.

Em cokwe aplicam-se as estratégias de espontaneidade, onde possível (Quadro 2), com base no protótipo, isto é, tornando as novas referencialidades unidades lexicais plenas, cujas flexões de número

$\overline{{ }^{16} \emptyset \text {-xikwola no }}$ cokwe vernacular diz-se zwolyaku-longesa (casa para o ensino); $\emptyset$-xiphitali é zwolyaku-wka (casa de tratamento), enquanto $\emptyset$-mbatata é designada por kathatha (batata). 
v. 11 (esp.)

103-119 ago. 2021

(plural) ocorrem, segundo Martins (1990), preferencialmente na $9^{a}$ classe $^{17}$.

Quadro 3 - Acomodação dos empréstimos

\begin{tabular}{|c|c|c|}
\hline \multicolumn{3}{|c|}{ Cokwe $\Rightarrow$ Cokwe (acomodação) } \\
\hline Singular & Plural (Classe) & Significado \\
\hline$\varnothing$-xikwola & ma-xikwola & escola(s) \\
\hline$\emptyset$-ngatu & ma-ngatu & gato(s) \\
\hline$\emptyset$-suka & $\varnothing$-suka & Açúcar \\
\hline$\emptyset$-saphatu & ma-saphatu (9) & sapato(s) \\
\hline$\varnothing$-pha(tele)dre & ma-pha(tele)dre (9) & padre(s) \\
\hline$\varnothing$-phulixa & ma-phulixa & polícia(s) \\
\hline mu-ngoso & mi-ngoso & negócio(s) \\
\hline$\varnothing$-kazaku & tu-zaku & casaco(s) \\
\hline$\emptyset$-xiphitali & ma-xiphitali & hospita(is) \\
\hline$\varnothing$-mbatata & ma-mbatata & batata(s) \\
\hline$\varnothing$-phatu & ma-phatu & pato(s) \\
\hline$\varnothing$-livulu & ma-livulu & livro(s) \\
\hline$\varnothing$-senowola & ma-senowola & cenoura(s) \\
\hline
\end{tabular}

Assim, confirma-se neste processo de acomodação (Quadro 3) que a variação da sílaba inicial dos nomes portugueses em prefixo $\emptyset$, na maioria dos nomes, corresponde a um mecanismo de integração (livulu, phatu, phulixa), cujo plural é realizado essencialmente com o prefixo ma da classe 9. Inclui-se neste processo outras estratégias, entre elas, a pré-nasalização (ngatu, mbatata), assim como a infixação ( $\varnothing$-xikwola, $\varnothing$-senowola), morfologicamente ou não representados, que concorrem para a atribuição de novas propriedades articulatórias ao nome. Desta forma, são respeitados os elementos morfológicos e semânticos, ainda que a variação dos radicais do léxico português seja um requisito sine qua non para a integração em cokwe. Daí entenderse também a $\emptyset$-senowola» ma-senowola na mesma classe. Segundo Mbangale (1994), Chicuna (2010) e Antunes, Correia e Gonçalves (2004), ocorre o processo de substituição, seguido de nasalização em mi-ngoso, na classe 2; redução em $\emptyset$-suka, integrado na classe 5 (por ser adequado aos nomes cujo plural representa massa ou tendentes a

${ }^{17}$ Segundo Martins (1990), "A maior parte dos nomes desta classe não têm prefixo no singular [...]. Alguns dos nomes que derivam das línguas europeias tomam lugar nesta classe." (MARTINS, 1990, p. 46). 
referenciar generalidades); já na classe 10, não denotando diminuição, a classe permite também a acomodação de outros nomes prefixados em ka, no singular, e tu, no plural.

Como se pode constatar, a classe dos prefixos nasalizados ng e mb são importantes recursos nas línguas nacionais e, em particular na língua cokwe, pois contribuem para a modificação (abrandamento da oclusividade ou intensidade sonora) e para a respetiva adaptação aos comportamentos fonéticos vernaculares. Esta versatilidade dos afixos faz com que a língua cokwe apresente algumas valências na sua articulação, sobretudo, de pronúncia/forma (phadre ou phatele) dependendo do nível sociocultural do indivíduo, isto é, do maior ou menor grau de influência e proficiência desta língua.

Finalmente, nota-se que, enquanto os morfemas sufixais são fundamentais para a flexão numeral dos nomes em português, o inverso ocorre na língua cokwe e em outras línguas bantu (MARQUES, 1983; MINGAS, 2000). São as classes nominais que determinam as alterações, flexões e o respetivo uso (categorização), sendo a flexibilidade, para todos os efeitos, a maneira do português europeu e do "angolar" concorrerem para o enriquecimento, inovação e "vitalidade"18 da língua cokwe. De facto, o cokwe surge como uma língua de comunicação alargada, tal como documentado por Inverno (2018, p. 91).

\section{Considerações finais}

Nota-se que, em função do contacto, as línguas portuguesa e cokwe gozam de diferentes estatutos, em consequência do valor sociopolítico que lhes são conferidos pelo governo angolano. E, em função disso, a língua portuguesa continua a ser uma ferramenta indispensável, a título experimental, no atual ensino das línguas nacionais e da língua cokwe, em particular, assim como no campo da investigação científica.

Hoje, como consequência do longo contacto e da aculturação das principais comunidades angolanas, a língua portuguesa (angolar) está patente nas demais línguas locais. Esta presença pode ser marcada ao nível da interferência, mas é sobretudo ao nível da complementaridade que a língua portuguesa exerce o seu domínio. As línguas nacionais apresentam insuficiências na referenciação dos desafios da modernidade

\footnotetext{
${ }^{18}$ Resulta da função identitária, âmbito de uso, nível de transmissão intergeracional, literatura disponível e perfil social de uso da língua. (LEWIS, SIMONS e FENNING, 2015, p. 23-26, apud INVERNO, 2018).
} 
v. 11 (esp.)

103-119 ago. 2021 sociocultural, e tal implicará a aceitação e integração de empréstimos lexicais, com maior realce para os do angolar, por este ser o português de maior contacto.

Algumas unidades lexicais presentes tanto nos manuais escolares, quanto nos meios de comunicação social estão integradas e acomodadas de acordo com as estratégias habituais nesta língua bantu, isto é, pelo processo de prefixação, obrigando à variação e/ supressão de morfemas na posição inicial, intermédia e final das unidades lexicais, de modo a conformar e acomodá-las em categorias já existentes. Retomando as questões colocadas anteriormente: 1) está o sistema linguístico da língua nacional cokwe preparado para este dinamismo? 2) É o sistema de classes nominais compatível com esta necessidade integracional? Entendemos que o sistema da língua cokwe apresenta as condições para o dinamismo resultante do contacto entre esta língua e a língua portuguesa. Admitimos que o sistema de classes nominais é compatível com esta necessidade de integração entre as duas línguas. No entanto, tratando-se de empréstimos, entendemos ser normal que alguns encontrem vários enquadramentos em outras propostas de classes nominais, de acordo com outros autores, o que nos desafia a estudos complementares.

De modo geral, conclui-se que este processo tem implicações na aquisição da expressão nominal na língua oficial, enquanto língua segunda, uma vez ser comum, em muitos casos o uso de sintagmas nominais não marcados. Tal deriva, necessariamente, no processo de ensino bilingue, o que implica uma reciprocidade de elementos das duas línguas. Esta reciprocidade ocorrerá quer ao nível oral mais comum), quer ao nível escrito (mais controlado pelos mecanismos existentes no ensino).

\section{Referências}

ANDRADE, E. de. Línguas africanas: breve introdução à fonologia e à morfologia. Santo António dos Cavaleiros: A. Santos, 2007.

ANGOLA. Constituição da República de Angola: promulgada em 05 de fevereiro de 2010. Luanda: Angola, 2010.

ANTUNES, M.; CORREIA, M.; GONÇALVES, R. Neologismos terminológicos na área da economia: processos mais frequentes em português europeu. Associação de Informação Terminológica (AiT), 2004. Disponível em: http:// www.iltec.pt/pdf/wpapers/2004-ait-neo econ.pdf. Acesso em: 11 nov. 2018.

BEVILACQUA, J. De caçadores a caça: sobas, Diamang e o Museu do Dundo. 
2016. Tese (Doutorado em História Social) - Faculdade de Filosofia, Letras e Ciências Humanas, Universidade de São Paulo. São Paulo, 2016. Disponível em: http://www.teses.usp.br/teses/disponiveis/8/8138/tde-25082016-132727. Acesso em: 6 jun. 2017.

CAPPELLO, H.; IVENS, R. De Benguela às terras de Iacca. Descrição de uma viagem na África Central e Ocidental. Vol. I. Lisboa: Imprensa Nacional, 1881.

CARIOCA, C. As funções sociais da língua e as políticas de difusão do Português no Timor-Leste. DELTA, São Paulo, v. 32 n. 2, ago. 2016. Disponível em: $\quad$ http://www.scielo.br/scielo.php?script=sci arttext\&pid=S010244502016000200427\&lng=en\&nrm=iso. Acesso em: 28 ago. 2020.

CARRASCO, A. Subsídios para o estabelecimento da norma do português em Angola. Monografia de licenciatura. Huila: ISCED, 1988.

CARVALHO, S. Convergência e divergência na acomodação dialetal: uma questão de identidade. UFPE/FALUB/UVA. 49-74. In: XVIII CONGRESSO NACIONAL DE LINGUÍSTICA E FILOLOGIA. 2014. Disponivel em: http://www. filologia.org.br/xviii_cnlf/cnlf/12/004.pdfFcarl. Acesso em: 11 nov. 2018.

CHICUMBA, M. A educação bilingue em Angola e o lugar das línguas nacionais. In: IV COLOQUIO INTERNACIONAL DE DOUTORANDO/AS DO CES. CABO DOS TRABALHOS. 2013. p. 1-10. Disponível em: https://cabodostrabalhos.ces. uc.pt/10/documentos/11.1.2 Mateus Segunda_Chicumba.pdf. Acesso em: 17 fev. 2017.

CHICUNA, A. Portuguesismos - Neologismos e sua dicionarização na língua kiyombe. In: MARÇALO, M. et al. Língua portuguesa: ultrapassar fronteiras, juntar culturas. Universidade de Évora. 2010. Disponível em: http://www. simelp2009.uevora.pt/pdf/slg1/06.pdf. Acesso em: 4 maio 2018.

COSSA, E. Línguas nacionais no sistema de ensino para o desenvolvimento da educação em Moçambique. 2007. Dissertação - Faculdade de Educação da Universidade Federal do Rio Grande do Sul, Porto Alegre. Porto Alegre, 2007. Disponível em: https://www.lume.ufrgs.br/bitstream/ handle/10183/10832/000601940.pdf. Acesso em: 28 jan. 2020.

DIÁRIO DA REPÚBLICA DE ANGOLA. Lei n.o 17 de outubro de 2016, série n. ${ }^{\mathbf{1} 170}$ Lei no17/16. Lei de Bases do Sistema de Educação, 2016.

DIAS, J. Caçadores, artesãos, comerciantes, guerreiros: os Cokwe em perspectiva histórica. A antropologia dos Tshokwe e povos aparentados. 2003. Disponível em: http://ler.letras.up.pt/uploads/ficheiros/7896.pdf. Acesso em: 23 jun 2017. p. 17-48.

EDUARDO, A. Expressões nominais genéricas num corpus oral do português de Angola. Dissertação de Mestrado. Lisboa: FCSH, 2016.

HAGEMEIJER, T. O português em contacto em África. 2016. p. 43-67. Disponível em: http://repositorio.ul.pt/bitstream/31040/1/Hagemeijer2016\%28MLP\%29. pdf. Acesso em: 3 fev. 2017.

INIDE. Projecto Estratégia de Inserção das Línguas Nacionais no Ensino. Luanda, 2015. 
v. 11 (esp.)

103-119 ago. 2021

118

INE. Censo Geral da População e Habitação. Luanda, 2014.

INE - Angola. Divulgação dos resultados definitivos das províncias do Cunene, Cuanza-sul, Bié e Bengo. 2016. Disponível em: http://censo.ine.gov. ao/xportal/xmain?xpid=censo2014. Acesso em: 15 jan. 2017.

INVERNO, L. Contacto linguístico em Angola: retrospetiva e perspetivas para uma política linguística. In: PINTO, P. F.; MELO-PFEIFER, S. Políticas Linguísticas em Português. Lisboa: LIDEL, 2018. p. 82-105.

JORGE, L. A colecção Henrique de Carvalho da Sociedade de Geografia de Lisboa à luz de um plano de estudo e conservação e restauro. Tese de mestrado. ISCTE, 2008. Disponível em: http://www.africafederation.net/HENRIQUE\%20 DE\%20CARVALHO.pdf. Acesso em: 7 ago. 2018.

KUKANDA, V. Diversidade linguística em África. Africa Studia: Revista Internacional de Estudos Africanos, n. 3, p. 101-117, 2000.

LIMA, M. A sociedade tchokwe ${ }_{2}$ a baixa de kassanji, os Jinga e a rainha Jinga. In: $1^{\circ}$ ENCONTRO DE REFLEXẪO SOBRE CULTURA E AMBIENTE NO LESTE DE ANGOLA. Associação de Naturais e Amigos do Leste. ASLESTE, [s.d.]. p. 37-60.

MANASSA, J. Lunda. História e sociedade. Luanda: Editora Mayamba, 2014.

MARQUES, I. Algumas considerações sobre a problemática linguística em Angola. In: ACTAS DO CONGRESSO SOBRE A SITUAÇÃO ATUAL DA LÍNGUA PORTUGUESA NO MUNDO. Vol. I. 205-223. Lisboa: Instituto de Cultura e Língua Portuguesa, 1983.

MARTINS, J. Elementos da gramática utchokwe. Lisboa: Ministério do Planeamento e da Administração do Território, Secretaria de Estado da Ciência e Tecnologia, Instituto de Investigação Científica Tropical, 1990.

MBANGALE, M. Empréstimos portugueses em Suaíli. Alguns aspectos da sua integração morfológica. Dissertação de mestrado. Lisboa: Faculdade de Letras da Universidade de Lisboa, 1994.

MINGAS, A. Interferência do kimbundu no português falado em Lwanda. Luanda: Edições Chá de Caxinde, 2000.

NOGUEIRA, R. Temas de linguística banta: dos elementos prefixados bantos. Vol. 3. Instituto de Línguas Africanas e Orientais: Anexo a Escola Superior Colonial, 1952.

NZAU, D.; VENÂNCIO, J.; SARDINHA, M. Em torno da consagração de uma variante angolana do português: subsídio para uma reflexão. Limite, n. 7 , p. 159-180, 2013. Disponível em: http://www.revistalimite.es/volumen\%20 7/ognzau.pdf. Acesso em: $14 \mathrm{fev} .2018$.

QUINO, A. A importância das línguas africanas de Angola no processo de aprendizagem da língua portuguesa. Monografia de licenciatura. Luanda: ISCED Universidade Agostinho Neto, 2005.

SANTANA, F. Formação de Angola e as resistências africanas. In: VIII ENCONTRO 
ESTADUAL DE HISTÓRIA. ANPUH. 2016. Disponível em: http://snh2011. anpuh.org/resources/anais/49/1476981752 ARQUIVO_FormacaodeAn olaeasResistenciasAfricanas.pdf. Acesso em: 2 jul. 2018.

SANTOS, E. Elementos de gramática quioca. Lisboa: Agência-Geral do Ultramar, 1962.

DECLARAÇÃo Universal dos Direitos Linguísticos. Lisboa: Campo das Letras. 2001.

VILELA, M. Gramática da língua portuguesa. Gramática da palavra. Gramática da frase. Gramática do texto/Discurso. 2. ed. Coimbra: Livraria Almedina, 1999.

ZAU, F. O bilinguismo e o multilinguismo. A realidade sociocultural que não devemos ocultar. In: XII ENCONTRO DA ASSOCIAÇÃO DAS UNIVERSIDADES DE LÍNGUA PORTUGUESA, AULP. Luanda. 2002. p. 182-183. 